\title{
Redes Criativas: os artistas visuais contemporâneos e sua relação com os direitos de autor
}

\author{
Creative Networks: contemporary visual artists and their relationship \\ with copyrights
}

Jamilla de Paula dos Santos Almeida ${ }^{1}$

Patrícia Oliveira Areas ${ }^{1}$

Pierre Barnabé Escodro ${ }^{1}$

${ }^{1}$ Universidade Federal de Alagoas, Maceió, AL, Brasil

\begin{abstract}
Resumo
Este artigo apresenta como foi desenvolvida uma pesquisa-ação de natureza descritiva e aplicada, na qual o método indutivo tem como foco analisar a abordagem de direito autoral vivenciada pelos artistas visuais atendidos pelo Projeto "Redes Criativas" do Serviço Brasileiro de Apoio às Micro e Pequenas Empresas em Alagoas (SEBRAE/ $\mathrm{AL}$ ), no município de Maceió (conhecido como Redes Sebrae), com o intuito de traçar um manual de direitos de autor para artistas visuais com linguagem acessível e simplificada que será disponibilizado nas redes sociais para download por meio de link.
\end{abstract}

Palavras-chave: Direitos de Autor. Artes Visuais. Economia Criativa.

\begin{abstract}
This paper presents how a descriptive and applied action research was developed, where the inductive method focuses on analyzing the copyright approach experienced by the visual artists assisted by the "Creative Networks" Project Brazilian Micro and Small Business Support Service in Alagoas (SEBRAE/AL), in the municipality of Maceió (known as Sebrae networks), in order to draw a copyright manual for visual artists with accessible and simplified language which will be made available on social networks for download via link.
\end{abstract}

Keywords: Copyright. Visual Arts. Creative Economy.

Áreas Tecnológicas: Direito Autoral. Artes Visuais.

\section{Introdução}

A cultura teve suas primeiras análises econômicas em uma revista acadêmica alemã no início do século XX, e suas nuances de interpretação que vinculavam às questões intelectuais, artísticas trazem uma percepção distinta sobre o "valor do produto" (VALIATI; CORAZZA; FLORISSI, 2011). 
Agregado a isso, a criatividade, como valor simbólico de dimensões múltiplas: artística, científica e simbólica (UNCTAD, 2010), é entendida assim:

Não existe uma definição simples de "criatividade" que englobe todas as várias dimensões desse fenômeno. De fato, no campo da psicologia, no qual a criatividade individual tem sido amplamente estudada, não existe consenso sobre a questão de a criatividade ser um atributo humano ou um processo pelo qual ideias originais são criadas. No entanto, as características da criatividade em diferentes áreas do empreendimento humano podem, pelo menos, ser articuladas. (MINC; ITAÚ CULTURAL, 2012, p. 3)

Avançamos para um conceito em permanente construção, que é a Economia Criativa, em que seus elementos basilares são ativos criativos que proporcionam desenvolvimento econômico e que perpassam por campos que vão das artes até a tecnologia (MORANDI et al., 2017).

Neste sentido, o questionamento da dimensão material das atividades culturais no mundo contemporâneo cresce em importância, diante da necessidade de se conhecer melhor a produção e o consumo de bens e serviços culturais da população, o desenvolvimento do mercado de trabalho do setor, a incidência na economia nacional e a sua contribuição no desenvolvimento econômico, os espaços físicos e os equipamentos da mais diversa ordem, como base empírica desenvolvimento de políticas públicas da cultura e da tomada de decisões dos gestores e especialistas que fazem parte dela. (LINS, 2009, p. 131)

O Mapeamento da Indústria Criativa ${ }^{1}$ no Brasil - Edição de $2016^{2}$ (que cobre o período entre 2013 até 2015), realizado pela Federação das Indústrias do Estado do Rio de Janeiro (FIRJAN) apontava que: "O mercado de trabalho criativo no país em 2015 é composto por 239 mil estabelecimentos e 851,2 mil profissionais formais. O PIB Criativo, no PIB Brasileiro cresceu de 2,56\% para 2,64\%, gerando uma riqueza de $\mathrm{R} \$ 155,6$ bilhões". Ainda nesse estudo tem-se a definição de quatro áreas que englobam 13 segmentos e que foram assim traçadas por especialistas que atuam em cada um dos setores e que auxiliaram na sistematização, a saber:

Consumo (Design, Arquitetura, Moda e Publicidade), Mídias (Editorial e Audiovisual), Cultura (Patrimônio e Artes, Música, Artes Cênicas e Expressões Culturais) e Tecnologia (P\&D, Biotecnologia e TIC). Por possuírem características semelhantes entre seus segmentos, esta agregação facilita a leitura dos movimentos e identificação de tendências. (FIRJAN, 2016, p. 13)

Assim, o insumo básico da Economia Criativa é a criatividade efetivada por meio da criação humana em que se conjugam fatores de compartilhamento e colaboração de saberes e práticas.

Nesse cenário, o Estado de Alagoas mantinha uma participação de trabalhadores da Cultura no percentual de $16,2 \%$, sendo maior do que duas vezes a representação média nacional 7,8\%, à época (FIRJAN, 2016).

\footnotetext{
${ }^{1}$ Criatividade e inovação empresarial analisados na perspectiva da arte, significados, experiências sensoriais, necessidades e desejos humanos que proporcionem qualidade de vida aos indivíduos e ao meio (FIRJAN, 2019).

${ }^{2} \mathrm{O}$ primeiro mapeamento foi publicado em 2012 e o mais recente em 2019. Ambos estão disponíveis no site da Firjan: https://www.firjan.com.br/EconomiaCriativa/pages/default.aspx.
} 
O British Council, em 2018, publicou em seu site uma Análise da Situação e Avaliação do Programa de Empreendedorismo Social e Criativo financiado pelo Newton Fund. Um dos estados pesquisados é Alagoas, que evidencia a diversidade da cultura popular e artística e, ao mesmo tempo, a fragilidade em sua preservação e disseminação:

Os agentes e as organizações culturais não estão bem conectados e nem preparados para trabalhar nos setores públicos e privados, a fim de demonstrar o valor que o setor cultural e criativo tem e poderia oferecer à economia e para melhorar o desenvolvimento do estado. Atualmente, o estado não publica dados oficiais sobre a Economia Criativa e cultural, e não tem planos para fazê-lo. Os administradores de cultura pública municipais reconhecem a importância da cultura como oportunidade para o desenvolvimento econômico, além do expressivo negócio de cana-de-açúcar do qual o estado é dependente. Em um nível estadual mais amplo, há menos entendimento das oportunidades significativas que a Economia Criativa e cultural poderia oferecer ao estado, além do turismo. Exceto pelas negociações com artesãos e secretarias de turismo, os administradores culturais públicos enfrentam dificuldades até mesmo para engajar outros stakeholders do governo e explicar a importância da cultura para o desenvolvimento econômico do estado. Falta entendimento do que seja a Economia Criativa entre os administradores públicos, que compreendem a cultura de uma forma mais ampla do que a criatividade. As ações e políticas desenvolvidas pela Secretária da Cultura de Alagoas e pela Fundação Cultural Maceió (os dois principais stakeholders públicos na cultura do estado) não alcançam e/ou não estimulam conexões entre a produção cultural $e$ as áreas relacionadas à Economia Criativa mais ampla, particularmente tecnologia e inovação. (FLEMING, 2018, p. 23)

Desse panorama, surge então, em $2017^{3}$, o Projeto "Redes Criativas", do Sebrae/AL, como um desafio na própria instituição que começa a perceber a carência de especialistas em gestão de negócios criativos no Estado, levando à contratação de um consultor de outra localidade.

A proposta de trabalho do projeto se lança a promover e aprimorar a gestão dos negócios, fortalecer o setor da economia criativa, além de proporcionar uma formação continuada e específica àqueles que empreendem nos segmentos de artes visuais, arquitetura, design, publicidade, comunicação, música e audiovisual.

O Projeto Redes é conduzido pela gestora Débora Lima e pelo consultor André Lira, que durante todo esse tempo realizaram um planejamento de atividades e de reuniões mensais que ocorreram no Município de Maceió, alternando entre a sede 4 do Sebrae/AL e espaços criativos dos próprios integrantes do projeto, onde ocorriam palestras, oficinas, cursos, inclusive visitas técnicas relacionadas às questões empresariais e às setorizações do mercado para economia criativa: acesso a crédito, consumo e experiência.

De acordo com o $2^{\circ}$ Relatório de Gestão e Monitoramento do Projeto Redes de 17/01/2019, que compreende o período de 02/01/2018 a 31/12/2018, foi possível mensurar a quantidade de empreendedores atendidos.

\footnotetext{
${ }^{3}$ Em dezembro do mesmo ano foi anunciado no site do extinto Ministério da Cultura (atual Secretaria Especial da Cultura, vinculado ao Ministério da Cidadania) que o outrora ministro Sérgio de Sá Leitão havia firmado publicamente uma parceria com o Sebrae Nacional, à época, presidido por Afif Domingos para a capacitação do setor de economia criativa. Houve o anúncio da criação do Centro Nacional de Referência em Empreendedorismo, Tecnologia e Economia Criativa, em São Paulo, com a proposta de formação contínua para empreendedores, gestores e executivos com a expectativa de impulsionar, promover e desenvolver o setor e inclusive lançando perspectivas para implementação do modelo no restante do país, o que ainda não foi efetivado com a mudança política no Executivo Federal desde 01/01/2019.

${ }^{4}$ Localizada à rua Dr. Marinho de Gusmão, n. 46, Centro, Maceió, AL. CEP: 57020-565.
} 
Quadro 1 - Mensuração dos Empreendedores no Projeto Redes

\begin{tabular}{|c|c|c|c|}
\hline Natureza JuRídica & Porte & Atendimentos & \multirow{6}{*}{ 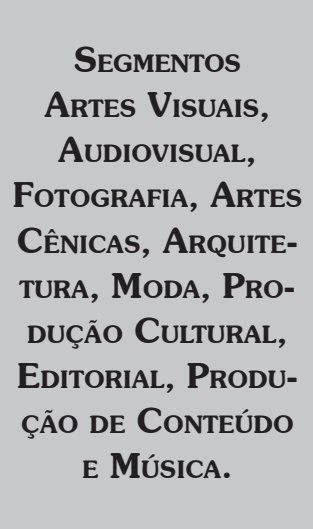 } \\
\hline $\begin{array}{l}\text { Microempreendedor } \\
\text { Individual (MEI) }\end{array}$ & $\begin{array}{l}\text { ME - Faturamento até } \mathrm{R} \$ \\
81.000,00 \text { por ano }\end{array}$ & 34 & \\
\hline Sociedade Empresária & $\begin{array}{l}\text { ME - Microempresa - } \\
\text { Faturamento até } \mathrm{R} \$ 360.000,00 \text { por ano }\end{array}$ & 15 & \\
\hline Sociedade Empresária & $\begin{array}{c}\text { EPP - Empresa de Pequeno Porte } \\
\text { Faturamento } 360.000,00 \\
\text { e } \mathrm{R} \$ 4,8 \text { milhões }\end{array}$ & 03 & \\
\hline Candidato a Empresário & - & 126 & \\
\hline Empreendedor Potencial & & 01 & \\
\hline
\end{tabular}

Fonte: Elaborado pelos autores deste artigo (2019)

Os empreendedores criativos não têm como obrigatoriedade ter um Cadastro Nacional de Pessoa Jurídica (CNPJ) constituído para sua participação no projeto, e a adesão ocorre de forma voluntária às reuniões mensais e aos grupos de WhatsApp mantidos com regras definidas para convivência e divulgação de atividades promovidas; além disso, as questões territoriais e culturais que cada um carrega em sua subjetividade são levadas em consideração nas análises grupais em que se constrói a perspectiva do pensamento sistêmico sobre o negócio, recursos, produtos, vendas, parcerias, saúde mental e o impacto da criatividade no entorno.

Em fevereiro de 2019, o Projeto Redes Sebrae transformou-se em eixos: com a percepção mais alargada da Economia Criativa, aproximou-se do Projeto Negócios de Impacto Social e Ambiental (NISA) e do Projeto Ecossistemas Criativos em Alagoas com o acompanhamento em grupos setoriais de Artes Cênicas, Música e Audiovisual, por meio das ações propostas no Planejamento Estratégico do Sebrae 2019/2020.

\section{Metodologia}

Por meio da realização de entrevistas com roteiro semiestruturado, foram identificadas as demandas dos artistas visuais acerca do direito autoral, realizando uma análise de conteúdo para composição do manual de boas práticas, em que os entrevistados foram quatro artistas visuais contemporâneos vinculados ao Projeto Redes Sebrae, na cidade de Maceió.

A amostra foi definida por julgamento, elaborada com base no $2^{\circ}$ Relatório de Gestão e Monitoramento do Projeto Redes Criativas 2019, que discrimina o segmento de Artes Visuais.

Como critério de inclusão da amostra, foram convidados a participar da pesquisa os artistas visuais contemporâneos que compõem o Projeto "Redes Criativas" do Sebrae/AL, no município de Maceió. Foram excluídos da supracitada amostra os indivíduos que trabalham prioritariamente com os seguintes segmentos: audiovisual, artes cênicas, arquitetura, moda, produção cultural, editorial, produção de conteúdo e música. 
Tal exclusão levou em consideração o objetivo específico deste trabalho, cujo cerne se concentra nos direitos de autor dos artistas visuais contemporâneos e na fluidez da comercialização de sua obra no mercado da economia criativa.

Após a submissão e aprovação do Comitê de Ética e Pesquisa da Universidade Federal de Alagoas (CEP/UFAL), por meio da Plataforma Brasil ${ }^{5}$, houve o convite e a disponibilidade dos indivíduos-alvo em participar da entrevista, sendo imediatamente informados sobre a identificação da pesquisadora principal e do objetivo da pesquisa. Antes da aplicação do roteiro semiestruturado, todos foram comunicados sobre as disposições do Termo de Consentimento Livre e Esclarecido (TCLE), que, em linhas gerais explicita o seguinte: caso sintam-se inibidos ou constrangidos, poderiam interromper sua participação na pesquisa a qualquer momento; os dados prejudicados seriam descartados, se preferissem.

Observa-se ainda que os dados e as informações prestados estão sendo apresentados com o consentimento de seus participantes, após sua autorização, única e exclusivamente, para fins desta pesquisa, e os resultados poderão ser publicados em quaisquer meios de disponibilização de informação, como: impresso, eletrônico, digital, radiofônico, televisivo, etc.

Houve a ciência de que a participação na pesquisa não enseja nenhum valor econômico, a receber ou a pagar; no entanto, caso tivessem quaisquer despesas decorrentes da participação na pesquisa, seriam ressarcidos.

Dessa feita, caso algum dos participantes se sentisse prejudicado por quaisquer questões relativas à pesquisa poderia ser indenizado após decisão judicial ou extrajudicial por mediação e/ou arbitragem pelos danos advindos de sua participação neste trabalho.

O protocolo de estudo de caso adotado seguiu a gradação exposta, com a finalidade de elevar a confiabilidade na pesquisa e garantindo que ela pudesse ser replicada por outros futuros pesquisadores: a) formulação do roteiro de entrevista semiestruturado; b) identificação dos artistas visuais atendidos pelo Projeto Redes Sebrae; c) realização de pesquisa documental por meio de folders, catálogos e sites dos espaços expositivos estatais, paraestatais e privados de Maceió; d) entrar em contato com os artistas visuais para agendar as entrevistas em seus espaços criativos e/ou ateliês; e) confirmação das entrevistas com dia, hora e local previamente agendado; f) realização das entrevistas semiestruturadas, bem como de observações in loco; g) coleta de dados de cada artista visual contemporâneo individualmente; h) gravação da entrevista com autorização dos entrevistados; i) transcrição na íntegra das entrevistas; j) envio das transcrições das entrevistas para os orientadores, a fim de que fossem revisadas; k) descrição de cada situação individualmente; e l) elaboração do manual de boas práticas a partir do estudo de casos.

A partir da análise concatenada do objetivo, foram elaboradas as questões da pesquisa que foram organizadas em cinco blocos, bem como seus elementos de análise descritos no quadro a seguir. 
Quadro 2 - Elementos da Pesquisa

\begin{tabular}{|c|c|c|c|}
\hline Constructos & $\begin{array}{l}\text { Quantidade } \\
\text { De Perguntas }\end{array}$ & Categoria & ANÁlise \\
\hline Dados Gerais do Artista & 05 & Perfil do artista & $\begin{array}{l}\text { Nome civil, nome artístico, identidade } \\
\text { de gênero, idade e escolaridade. }\end{array}$ \\
\hline $\begin{array}{c}\text { Sobre a } \\
\text { Relação Artista - } \\
\text { Artes Visuais }\end{array}$ & 10 & $\begin{array}{l}\text { Aprendizagem } \\
\text { artística }\end{array}$ & $\begin{array}{c}\text { Construção da trajetória artística a } \\
\text { partir das experiências vivenciadas } \\
\text { pessoais e profissionais/Conhecimento } \\
\text { apreendido e compartilhado a partir } \\
\text { da convivência e estudos com outros } \\
\text { artistas ou em escolas de arte/A } \\
\text { interface orgânica entre a criação e a } \\
\text { exposição das obras de arte/Finalidade } \\
\text { da utilização das redes sociais. }\end{array}$ \\
\hline $\begin{array}{c}\text { Sobre a } \\
\text { Formalização do Trabalho } \\
\text { Intelectual Desenvolvido } \\
\text { pelo Artista }\end{array}$ & 09 & $\begin{array}{l}\text { Características } \\
\text { do CNPJ }\end{array}$ & $\begin{array}{l}\text { A decisão de se ter ou não um } \\
\text { CNPJ para a execução de suas } \\
\text { atividades/Identificação de parceiros, } \\
\text { funcionários, estrutura, porte e clientes/ } \\
\text { Identificação dos produtos, serviços } \\
\text { e obras de arte disponibilizadas. }\end{array}$ \\
\hline $\begin{array}{l}\text { Relação do Artista Visual } \\
\text { Contemporâneo com } \\
\text { os Direitos de Autor }\end{array}$ & 16 & $\begin{array}{l}\text { Percepção do } \\
\text { artista com o } \\
\text { Direito Autoral }\end{array}$ & $\begin{array}{l}\text { Percepção de proteção contra } \\
\text { reproduções não autorizadas/O } \\
\text { entendimento do Direito Autoral aliado } \\
\text { ao cotidiano de criação, exposição, } \\
\text { venda, licenciamento cessão e doação } \\
\text { das obras/Se há dificuldade em } \\
\text { relação ao acesso do conteúdo de } \\
\text { Direito Autoral/ Se há o conhecimento } \\
\text { sobre o creative commons. }\end{array}$ \\
\hline $\begin{array}{l}\text { Acesso e Consumo de } \\
\text { Informações por meio de } \\
\text { Conteúdo Físico e Digital }\end{array}$ & 08 & $\begin{array}{l}\text { Observação } \\
\text { da leitura } \\
\text { informacional } \\
\text { do tempo e da } \\
\text { realidade em que o } \\
\text { artista está inserido }\end{array}$ & $\begin{array}{l}\text { Relação com o acesso e o consumo } \\
\text { de informações por meios físicos } \\
\text { ou digitais/Se há a manutenção do } \\
\text { hábito da leitura de livros/Se com } \\
\text { alguma frequência compartilha } \\
\text { conteúdos de Artes e de Direito } \\
\text { Autoral/Se mantém o interesse em } \\
\text { participar de cursos, palestras e } \\
\text { vivências artísticas com essa temática } \\
\text { transdisciplinar/Como o conteúdo } \\
\text { técnico de Direito Autoral pode } \\
\text { aproximar-se do cotidiano artístico. }\end{array}$ \\
\hline \multicolumn{4}{|c|}{ Totalizando: 48 perguntas } \\
\hline
\end{tabular}

Fonte: Elaborado pelos autores deste artigo (2019)

Buscou-se, com os itens anteriormente elencados, traçar uma análise do perfil dos artistas visuais contemporâneos que compõem o Projeto Redes Sebrae; em seguida, por parentesco de sentido, avançou-se na percepção da aprendizagem e identificação do ser artista, como ocorre à aproximação e o entendimento dos Direitos Autorais vinculados a sua criação artística e por fim o interesse, o acesso e o consumo de informações.

Quanto ao lapso temporal, teve um corte transversal, pois a coleta de dados ocorreu em momento específico do calendário ocidental, tal qual uma obra de artes visuais realista em que o (a) modelo posa para sua composição de forma única (SAUNDERS, 2009). 
As entrevistas foram gravadas no sistema de captação de voz e som humanos do smartphone Xiaomi Redmi 6 PRO que pertence à pesquisadora principal e o conteúdo digital dos áudios está armazenado em nuvem, como também foram feitos apontamentos manuscritos em papel à caneta durante a aplicação do roteiro.

A seguir, o Quadro 3 apresenta, de forma sistematizada, quais artistas foram entrevistados, em qual ordem, a data que ocorreu a entrevista, o período de início e término, bem como a duração total e o local no município de Maceió.

Quadro 3 - Sistematização da Aplicação do Roteiro de Entrevista

\begin{tabular}{|c|c|c|c|c|c|c|}
\hline Artista & $\begin{array}{c}\text { ENTREVISTA } \\
\text { NúMERo }\end{array}$ & Data & $\begin{array}{l}\text { INícIO DA } \\
\text { ENTREVISTA }\end{array}$ & $\begin{array}{l}\text { TÉrminO DA } \\
\text { ENTREVISTA }\end{array}$ & DURAÇÃo & LoCAL \\
\hline Primeira/o & 01 & 01/07/19 & $15 \mathrm{~h} 30 \mathrm{~min}$ & $16 \mathrm{~h} 52 \mathrm{~min}$ & 1h22min & Casa-ateliê \\
\hline Segunda/o & 02 & 01/07/19 & $19 \mathrm{~h} 20 \mathrm{~min}$ & $20 \mathrm{~h} 05 \mathrm{~min}$ & $45 \mathrm{~min}$ & Casa-ateliê \\
\hline Terceira/o & 03 & 02/07/19 & $16 \mathrm{~h}$ & $17 \mathrm{~h} 12 \mathrm{~min}$ & 1h12min & Casa-ateliê \\
\hline Quarta/o & 04 & 02/07/19 & 23h09min & 00h33min & 1h24min & Casa-ateliê \\
\hline
\end{tabular}

Fonte: Elaborado pelos autores deste artigo (2019)

A elaboração do roteiro de entrevista foi estruturada a partir do referencial teórico e da vivência pessoal da pesquisadora principal como trabalhadora da arte, no segmento de Artes Visuais desde 2001.

Ressalte-se que os orientadores tiveram acesso a esse primeiro arquivo, do qual, na sessão de orientação por web conferência, foram sugeridos alterações e acréscimos. Após esses ajustes, a segunda versão do roteiro ficou estabelecida como definitiva, pois atendia à coleta de dados de forma aprofundada, indicando a concretização do objeto da pesquisa, sendo esta submetida e aprovada pelo CEP/UFAL.

Para que haja a ratificação da validade e da confiabilidade da pesquisa, foi estruturado um planejamento (YIN, 2010): 1) composição do projeto de pesquisa - justificativa aos orientadores de a temática de artes visuais e de o direito autoral entrelaçados serem importantes para a classe artística e para sociedade; 2) submissão do projeto, roteiro de entrevista, TCLE e demais documentos ao CEP/UFAL; 3) coleta de dados - aplicação presencial do roteiro semiestruturado; 4) elaboração e manutenção em nuvem de um banco de dados com as áudios-gravações e as transcrições; 5) envio do conteúdo transcrito aos orientadores para realização das revisões; 6) análise dos dados; e 7) desenvolvimento de um manual de boas práticas.

Ao se propor a realização de uma pesquisa, é sabido que há limitações relacionadas ao método empregado, ao tempo destinado à realização, à hermenêutica na análise de dados, bem como ao acesso singular aos participantes. Mas, cientes das limitações, foi possível executar com êxito a proposta apresentada.

Levou-se em consideração os riscos da suspensão/encerramento do trabalho se houvesse um caso de força maior, na cidade de Maceió, que provocasse uma hecatombe de artistas visuais ou afundamento do território onde se localizam os ateliês ou espaços criativos que inviabilizariam o prosseguimento por tempo indeterminado, mas esse fato não ocorreu.

Foi analisado o conteúdo dos dados provenientes da aplicação do roteiro semiestruturado da seguinte maneira: 1) transcrição individual na íntegra das entrevistas, sendo que, para cada 
30 minutos de oitiva da áudio-gravação, foi necessário 1h para transcrever o texto em Word; 2) organização das transcrições, com verificação do conteúdo em folders, catálogo e sites dos espaços expositivos estatais, paraestatais e privados de Maceió; 3) tratamento e interpretação do conteúdo, verificando se havia a ocorrência da problemática comunicacional da legislação autoral, que tem como destinatário o artista visual contemporâneo; e 4) elaboração de material instrucional específico para artistas visuais, com a temática dos Direitos Autorais.

\section{Resultados e Discussão}

Foram convidados quatro artistas visuais contemporâneos integrantes do Projeto "Redes Criativas" do Sebrae/AL, na cidade de Maceió para participar desta pesquisa qualitativa como estudo de caso.

Salientando-se que por se tratar de uma análise com rigor científico, em que pese não existir um número ideal, é satisfatória a aceitação de quatro a dez casos para gerar teoria, ficando comprometido o estudo, se tiver um número menor que quatro ou maior que 10, devido à dificuldade de mensuração do volume de dados (EISENHARDT, 1989).

Um mundo de papel, de cola e de cor: em sua memória afetiva, a primeira artista entrevistada recorda que desde pequena ficava rabiscando, sendo motivada pela mãe que juntava de forma espontânea os filhos, primos e vizinhos para desenhar sem ter a pressão de "ficar bonito", apenas para fazer brincadeiras.

Em sua família, a mãe e o avô materno tinham identificação com a Arte e isso se alastrou a outros membros, além de primos que atuam na área de arquitetura.

Nos anos de 1990 foi estudar no Ateliê do artista visual, Salles, no bairro do Prado, no centro da cidade. Nessa época, também buscou ter aulas aproximadamente por dois meses no Ateliê do artista visual, Pierre Chalita e, em seguida, foi estudar escultura em concreto (técnica de barro escultural em que modelava e em sequência transferia para o concreto) com outro artista que morava no Tabuleiro dos Martins e possui algumas esculturas de sua autoria no Terminal Rodoviário de Maceió.

Na jornada de experimentações artísticas, até definir a técnica predominante em sua obra, passou pelo desenho, pelo pastel, pela pintura a óleo, pela pintura com tinta acrílica, mas em nenhum destes conseguia sentir a identificação completa e o pertencimento que tinha necessidade em seu trabalho.

Entre 2006 e 2007 fez um curso no Museu Théo Brandão com o mestre Vilinba em que experienciou a técnica escultórica que utiliza de forma mais desenvolvida na papietagem.

Após fazer o curso de escultura, escolheu sua técnica ao definir o papel machê como a estrutura de sua obra.

Como referenciais artístico-visuais rememora Picasso, Miró, Gaudí e, devido ao papel marchê, tem acompanhado o trabalho no Instagram dos artistas@carolwmache, @julianabollini e @gustavoaimar.

Seu ateliê sempre foi individual e caracteriza-se por ser uma casa-ateliê que está sendo reestruturada para se tornar mais ampla e com mais incidência de luz diurna e vento. As Artes 
Visuais não são fonte exclusiva do seu sustento e pesquisa, concorrendo com as atividades desempenhadas no cargo de psicóloga concursada do Município de São Sebastião/AL.

Em 2008 realizou a sua primeira e única exposição individual no Museu Théo Brandão, intitulada "Mundo de Papel", com 32 esculturas e, em seguida, vieram muitos convites para participar de exposições coletivas no Estado, mas a artista nunca concorreu a nenhum edital de ocupação de espaço expositivo.

Para disseminar o seu trabalho, utilizava panfletos e as próprias exposições para divulgar as obras e as oficinas que ministrava. Depois da popularização das redes sociais, que ela utiliza para divulgar e vender, de forma sutil, ela menciona:

Mas não dispenso hoje essa abordagem de ir aos locais que você acredita que está seu público com os panfletos e estabelecer relações, pois o Facebook hoje está limitando muito a divulgação e para que seu post tenha algum alcance, é necessário promover. Enquanto eu não consigo regular meu Face e meu Instagram para determinado público, que é o que estou vendo com o pessoal do SEBRAE (essa calibração), tem muita coisa que a gente faz errado ou não faz. Acredito que minha divulgação irá melhorar.

Mantém-se ativamente no Instagram com o perfil artístico, tendo mais de 700 seguidores e engajamento ${ }^{6}$ nas suas postagens; no Facebook, sua rede ultrapassa 500 amigos.

A caricatura e o riso: o segundo artista entrevistado rememora que seu interesse pelas artes visuais surgiu aproximadamente aos 11 anos, quando um grupo de garotos, que morava na mesma rua onde ficava localizada sua residência, na Cidade Ocidental em Goiás, começou a desenhar junto.

Na família, teve no seu irmão mais velho, que é ator e mímico, a figura que lhe inseriu no meio artístico de Taguatinga e Brasília entre a sua infância e a adolescência.

No início dos anos 1990, quando já residia em Maceió, foi estudar desenho no Cenarte ${ }^{7}$ com o artista José Tenório e complementa: "Fiz alguns trabalhos com o Rosivaldo Reis, a caricatura que eu já gostava desde a infância e eu pesquisei muitos 'dos grandes' em jornais e revistas, o que me direcionou muito no desenho".

A escolha pela técnica apresentou-se naturalmente, pois o desenho já havia se inserido no cotidiano e, a partir dele, começou a entender a existência das Artes Visuais, ao experimentar a pintura, a modelagem $e$ a intervenção.

Como referenciais artístico-visuais mais antigos, aponta o Mickey, de Walt Disney, e as charges dos irmãos Caruso, além de Rosivaldo Reis e Rogério Gomes na criação artística contemporânea e a convivência com a artista Adriana Jardim. Nas redes sociais, acompanha os trabalhos de Vick Muniz, Adriana Varejão, Kobra e os Gêmeos, pelo fato de todos trabalharem com obras em grandes dimensões.

No início da carreira não dispunha de recursos financeiros para ter seu próprio Ateliê, mas frequentava bastante o do artista Rosivaldo Reis, sendo seu espaço de criação os cômodos de sua casa.

Junto às Artes Visuais, o artista também trabalha com comunicação visual para manter-se e realizar suas pesquisas. Sua primeira exposição coletiva foi em 2009, denominada "7 Peca-

\footnotetext{
${ }^{6}$ Termo utilizado para comentários, envolvimento e interação a partir de uma postagem feita por um indivíduo em suas redes sociais

${ }^{7}$ Centro de Belas Artes de Alagoas criado em 1982 por Bráulio Leite Júnior e mantido pelo Governo do Estado.
} 
dos", que ocupou o espaço da Galeria Sesc Centro em Maceió, e a primeira individual foi em 2016, caricaturas de "Mestres Alagoanos", no Complexo Cultural do Teatro Deodoro. Participou e ganhou em $1^{\circ}$ lugar no Concurso Ecoarte da Secretaria Municipal do Meio Ambiente, em Maceió, também em 2009.

$\mathrm{O}$ artista utiliza as redes sociais, por meio de perfis pessoais que utiliza como um portfólio para divulgar sua atuação artística, disponibilizando através daqueles as imagens de seus desenhos em papel, desenhos digitais ou os murais encomendados.

Mantém-se ativamente no Instagram com o perfil artístico, tendo mais de 1.400 seguidores e engajamento nas suas postagens; no Facebook, sua rede ultrapassa 1.800 amigos.

As mãos que brincam com o traço: a terceira artista entrevistada rememora que seu primeiro contato com as Artes Visuais se deu na infância:

Na verdade, a minha história está ligada ao fato de eu ser descendente de artesãos. Meu avô era sapateiro na cidade onde eu nasci, Timbaúba, e ele exportava sapatos para o exterior. Aí eu comecei a ter essa relação com o fazer artístico. Sapatos de couro, perfeitos, igual aos de loja... Era uma produção muito grande na cidade inteira. Ele tinha um ateliê. Minha avó era costureira, então essa coisa do interior, de estar em Pernambuco e essa relação com a arte em si, da convivência com a arte em Pernambuco da infância até a morte.

E que durante toda a sua vida esteve ligada a olhar, ver e enxergar a Arte. Em sua família, a mãe costurava e pintava a óleo e o pai desenhava. Eles possibilitaram acessos aos outros segmentos artísticos: "A música e a literatura sempre foram muito presentes em casa, todos leem muito. E eu aprendi a ler visualmente as frases e a poesia através da Literatura. Por isso, terminei no caminho como ilustradora".

No Colégio de Freiras que frequentou, seus pais foram instigados a procurar um curso de desenho para auxiliar em seu processo de dislexia, identificado por testes realizados por uma psicopedagoga. Participou, na fase de transição entre a adolescência e a juventude, de cursos promovidos pela Tinta Acrilex no Recife e chegou a ganhar, em um concurso de pintura promovido, a primeira caneta que estava em teste e que desenhava em camisetas:

Depois tentei fazer aqueles cursos que eram da Escola de Belas Artes, mas não passei. E aí fui estudar pintura no Forte do Brum, no Cais. Montei exposição e fiz várias coisas. Depois fui estudar no Ateliê do Jacques Wayne (que era um pintor que ficou exilado uns 20 anos durante a Ditadura brasileira na Amazônia com os índios) e foi a relação mais importante que eu tive nessa transição de adolescente para adulta, pois ele viu que eu não tinha muita paciência de estudar por que eu tinha essa coisa compulsiva de produzir e vender. E a busca de pegar rápido, com a linguagem rápida visual. Então, ele percebia que eu não estava preocupada de fazer o cálculo do rosto por que não era aquilo que eu queria. E me pediu que prometesse a ele que eu não deixaria de produzir arte mais na vida e em seguida eu abandonei o curso.

Em sua trajetória, foi realizando alguns cursos, como o de extensão em escultura, promovido pela Universidade Federal de Pernambuco, de reciclado com o Professor Pedrosa, os do Museu de Arte de São Paulo, além de algumas aulas experimentais em instituições e em museus.

A escolha pela técnica de trabalho/pesquisa em Artes Visuais que utiliza: 
Foi acontecendo naturalmente por que é uma necessidade conforme você vai vivenciando, mas tem a ver com o que eu estava buscando também, até você chegar numa outra linguagem que vai te chamar a atenção e você vai experimentar também. Então, se você imaginar que o meu primeiro contato foi pegar em formão com 3 anos de idade foi uma consequência de uma história de vida. Mas eu poderia ter passado a vida toda só entalhando. E aí vem o fazer artístico lá da minha mãe que ensinava a gente a fazer a cola com grude, então tudo que a gente queria fazer utilizávamos o que tinha em casa. Então, a minha própria necessidade de sobreviver conforme eu fui fazendo mais arte... Eu fui produzindo conforme eu tinha acesso a materiais em casa. Como eu tinha habilidade para mexer em madeira, para fazer com papel, para fazer a cola, para pintar. Para mim era o que eu tinha, eu ia fazendo. A primeira vez que fui a uma Bienal de São Paulo que eu vi uma instalação de uma caixa de fósforos. Até hoje eu crio obras com palitos de fósforo. Por que meu maior sofrimento quando criança era jogar o palito de fósforo fora, pois eu via que era um pedacinho de uma célula de uma árvore, aquilo era sofredor: cortar uma árvore toda e transformar aquilo ali num pedacinho de madeira todo perfeito, cortado. Não é o produto final, mas o caminho até se chegar a essa árvore. Esse olhar da Arte faz o diferencial.

Como referência, indica os artistas populares como Chico da Silva, Bajado e complementa: "A família do Bajado pode/deve ser pobre, mas alguém que tem um Bajado pode valer um dinheiro. É muito louco isso!". Durante a adolescência conheceu as obras de Salvador Dali e, em sua atual fase, que se relaciona à Terra, menciona Franz Krajcberg, por ter trabalhado com restos de troncos e raízes de árvores, além de acompanhar Vick Muniz e acessar frequentemente o Instagram para buscar mais inspiração.

As artes visuais são sua fonte exclusiva de sustento e pesquisa e só teve uma oportunidade em que compartilhou o seu ateliê com mais dois amigos, em 1999, no Jaraguá8; antes e depois disso, seu espaço de trabalho sempre foi individual e caracteriza-se por ser uma casa-ateliê: "Porque eu sempre busquei ter o meu Ateliê e minha mãe me estimulou... eu quebrava todas cerâmicas da minha casa, arranhava os vidros da sala, tinha uma coisa estrutural que era difícil para os outros".

A artista concorreu em dois editais nacionais, o primeiro foi o do Centro Cultural da Caixa em São Paulo, em 2001:

Quando eu ganhei o edital, podia escolher e acabou ficando no vão livre do MASP por que a proposta era que fosse a céu aberto. Eram lonas com rosto, era a exposição 'Caras $3 \times 4$ '. Inclusive no convite, quem assinou e fez um poemazinho foi o Delson Uchôa.

Ainda em São Paulo, o segundo edital em que concorreu foi:

[...] para ocupação da Sede da Caixa da Praça da Sé, o museu. Eles uniram ao Projeto Bem Eficiente que era de uma socióloga, na época do Governo Lula, então eles pegavam vários ônibus e traziam os jovens das periferias para passar o dia no museu: visitavam o Museu da Caixa, da Carmen Miranda, a minha exposição e tinham uma oficina comigo, depois lanchavam e o ônibus levava de volta para casa. Isso aconteceu durante um mês, mas tudo tinha um sentido por que na minha exposição as obras eram compostas por materiais que eu catava no metrô da Barra Funda. E tinha acontecendo na mesma época um Projeto da Martha Suplicy com os carroceiros.

$\overline{{ }^{8} \text { Bairro portuário na região central de Maceió. }}$ 
Participou também da Bienal Naif do Sesc Piracicaba e dos vários editais dos Sesc no Nordeste que contemplavam exposições e oficinas.

Para disseminar seu trabalho, utiliza as redes sociais para que o público conheça a multiplicidade dos seus traços e segue:

Eu tomo muito cuidado. Na verdade, eu prendo muita coisa minha ainda. Tenho cuidado com essa questão de reproduzir. Porque tenho muitas coisas que pretendo transformar em produtos no futuro, então não saio publicando à toa. Sei também que a partir do momento que eu publico ela está registrada ali e tem a questão de data e o que vem após a minha publicação, veio depois. Então quando eu entendi isso, fiquei um pouco mais aliviada ao fazer as publicações. Eu tento separar dos "Produtos Maracajá" as publicações para que as pessoas vejam um pouco de tudo que produzo (esses produtos são réplicas e reproduções de tudo que eu já fiz) e isso está diretamente ligado ao Direito Autoral.

Mantém-se ativamente no Instagram com o perfil artístico, tendo mais de 1.400 seguidores e o de produtos da sua marca com mais de 500 seguidores e engajamento nas suas postagens; no Facebook, sua rede pessoal ultrapassa 2.000 amigos, além de manter uma fanpage.

A fotografia-sensível: o quarto artista entrevistado se enxerga como interessado pelas Artes Visuais desde quando consegue se lembrar: "Eu me vejo fotografando desde sempre. Sempre gostei muito de desenhar... Via as cenas e ficava retratando na minha cabeça. Mas eu nunca me imaginei vivendo da fotografia".

Em sua família, a figura paterna laborava com arte no teatro e no ato de escrever, mas o artista afirma que sua identificação artística não está entrelaçada a essa história, pois sempre gostou, independentemente da Arte, do cinema, e aos 11 anos, devido à timidez, já quis ter um violão para conseguir se expressar, o que o incentivou a formar um grupo musical aos 24 anos: "Eu tenho uma banda há 20 anos, chama SINSINHOR (Hardcore com as nuances do forró, do xaxado com as coisas que a gente tem aqui). Agradava, mas não era uma coisa para tocar em barzinho e ganhar dinheiro".

Recentemente, fez o curso de História da Arte do Mundo e História da Arte do Brasil com a professora Socorro Lamenha no Cenarte, mas antes disso, na adolescência: "Quando eu fiz edificações na Escola Técnica, a parte que eu mais gostava era projeto arquitetônico, pois nos meus projetos eu só tirava 10 (porque eu era muito chato e eu ficava fazendo até as telhinhas, se deixassem)".

Entre todas as suas experimentações que passaram pelo web design, letreiros à mão até a graduação em Publicidade, foi o encontro com o professor Pedro Simonard, na aula de introdução à fotografia, que impulsionou a definição da sua técnica de trabalho: "Eu senti um poder estúpido quando dominei a câmera, tipo um moleque que começa a correr...que sabe que pode correr, ir onde quiser, fazer o que quiser. [...] A fotografia me deu um poder que nunca tive na vida".

Como referenciais, o artista define que não gosta de se prender a nada especificadamente: "A maioria dos fotógrafos vê a obra do Salgado e acha maravilhosa, mas eu faço uma foto, me engrandeço e penso: isso aqui está a cara das coisas do Salgado, mas depois da foto pronta, eu enxergo isso. Eu não fiz a foto pensando isso".

Seu espaço de trabalho é individual e caracteriza-se por ser uma casa-ateliê e, atualmente, as artes visuais são sua fonte exclusiva de sustento e de pesquisa. 
Em 2018, realizou sua primeira exposição individual, "Um foco, antes do foco", no Café da Linda (localizado na entrada principal do Teatro Deodoro), mas antes participou de algumas coletivas a convite do artista Levy Paz e complementa: "Não sei fora, mas em Maceió muitas coisas ainda acontecem relacionadas 'a panela', se você está transitando naquele meio de pessoas que são agraciadas com convites, apadrinhamentos, etc. Isso tendo talento ou não, fazendo o melhor ou não".

Para disseminar seu trabalho, basicamente utiliza as redes sociais:

Geralmente, de todos os trabalhos que faço, eu publico três fotografias no Instagram (que é hoje o local que tem mais visibilidade para o meu tipo de trabalho por que as hashtags lhe proporcionam um posicionamento e você acaba sendo visto no Mundo). É uma coisa meio perdida para ver se outros clientes veem e te contratam para algum trabalho e ao mesmo tempo para ser visto em outros lugares do Mundo, meio que contar com a sorte, né. Não é o melhor caminho, mas a gente acaba indo, na falta da viabilidade financeira, a gente acaba meio que tentando a sorte. Só que hoje em dia tanto o Instagram quanto o Facebook não dão a mesma visibilidade. Há uns 02/03 anos atrás eu publicava uma foto e chegava a 700/800 curtidas no Facebook. Eu já publiquei foto de gente famosa (de alguma coisa que eu cubro) e só teve cinco ou dez curtidas. O problema não está na foto ou no artista. O problema está na restrição, essas redes fazem para lhe obrigar a patrocinar sua publicação. Aí dificulta um bocado por que quando a gente não tem como expor dessa outra forma que seria estar nas Galerias reais, estar nos editais, ser convidado para expor.... A Galeria que a gente tem é o Instagram.

Mantém-se ativamente no Instagram com o perfil artístico, tendo mais de 1.800 seguidores e engajamento nas suas postagens; no Facebook, sua rede de amigos é extensa, assim como na fanpage.

Analisando os casos apresentados, levando em consideração o perfil do artista, a aprendizagem artística, as características do CNPJ, a percepção do artista com o Direito Autoral e a observação da leitura informacional do tempo e da realidade em que o artista está inserido, é possível encontrar os resultados a seguir descritos.

A faixa etária dos artistas entrevistados é entre 44 e 51 anos, todos são residentes em Maceió, sendo que um deles nasceu em São Paulo, um em Goiás e um nasceu em Pernambuco.

A pesquisa conseguiu que metade do seu universo de indivíduos-alvo fosse do sexo masculino e a outra metade do sexo feminino, conseguindo paridade, no que se refere ao sexo biológico. Com relação à escolaridade, dois possuem nível superior completo, um nível superior incompleto e um possui ensino médio incompleto.

Sobre a aprendizagem da Arte, a maioria dos artistas narra que ainda durante a infância teve contato com a Arte em seus lares, indicando algum familiar como a pessoa que instigou ou proporcionou algum tipo de experiência artística. Além disso, todos eles frequentaram espaços criativos, escolas de Arte ou Ateliês de outros artistas durante a juventude e a maturidade, apontando que a escolha da sua técnica de trabalho ocorreu de forma orgânica diante das influências e referências que foram gestadas em seu animus.

E, na carreira profissional, todos já expuseram de forma individual e coletiva, sendo que apenas dois concorreram em editais públicos. 
Os artistas mantêm como espaço de criação individual sua casa-ateliê, além de atualmente terem inequivocamente nas redes sociais um local de divulgação de suas obras. Sendo que dois vivem exclusivamente do seu trabalho artístico e dois mantêm atividades laborais concorrentes com sua carreira nas artes.

Verificou-se que todos os artistas têm um CNPJ ativo com natureza de Microempreendedor Individual (MEI), pois queriam se tornar prestadores de serviços para o Poder Público e para o Sistema S, além de afirmarem que é uma necessidade do mercado, mas não possuem funcionários no regime da Consolidação das Leis do Trabalho (CLT). Em relação à Classificação Nacional de Atividades Econômicas (CNAE), tem-se: primeiro(a) entrevistado(a) - 8592-9/99 Ensino de arte e cultura não especificado anteriormente; segundo(a) entrevistado(a) - 82.30-0-01 Serviços de organização de feiras, congressos, exposições e festas; Terceiro(a) entrevistado(a) - 47.89-0-03 Comércio varejista de objetos de arte; e quarto(a) entrevistado(a) - 74.20-0-01 Atividades de produção de fotografias, exceto aérea e submarina.

Todos mantêm uma presença digital no Facebook e no Instagram, tendo como clientes prioritariamente pessoas comuns que veem os trabalhos e se interessam, quer seja nas exposições ou nas redes sociais.

\section{Considerações Finais}

Com relação à percepção do artista visual com o Direito Autoral, o cenário mostra que todos têm uma compreensão panorâmica sobre a matéria, mas encontram dificuldades em se inteirarem e compreenderem mais a respeito, pois em uma pesquisa rápida utilizando o termo "direito autoral" no Google, no dia 10 de julho de 2019, houve a disponibilização de mais de 14 milhões de resultados em pouco mais de 66 segundos.

Esse mar de conteúdos acaba provocando um não diálogo pelas dificuldades de seleção sobre o que é relevante e aborda sobre a linguagem e com o fazer diário desses artistas, que têm uma aprendizagem mais ligada aos interesses visuais, conforme aponta a narrativa de todos os participantes da pesquisa; nenhum deles se sente protegido em relação à reprodução não autorizada de seus trabalhos.

Nenhum dos indivíduos-alvo demonstrou conhecimento aprofundado ou que já havia utilizado as licenças Creative Commons em alguma de suas criações e/ou disponibilizações de imagens nas redes.

Contudo, usam as redes sociais e a internet para divulgar seus trabalhos, apesar do risco e do medo de cópias e a ciência da falta de controle.

A artista que tem uma percepção mais ampla da matéria, por ter sido ilustradora de uma grande editora sediada em São Paulo, narra que, ao regressar ao Nordeste, observou que tanto os gestores culturais quanto os gestores em diversos órgãos e secretarias pouco abordam a temática e não fazem cumprir o que seria estritamente escorreito com relação à legislação vigente, traçando um paralelo com a falta de acesso ao conhecimento da matéria por esses servidores públicos.

No contexto do acesso e do consumo informacionais, todos os artistas têm acesso à internet, sendo que três deles assistem a noticiários televisivos, além de acesso à mídia digital, e um se 
informa apenas de conteúdo digital. Em relação ao hábito de leitura, dois mantêm de forma contínua o acesso a livros.

Nas redes sociais, todos costumam compartilhar conteúdos alusivos às Artes, prioritariamente, rememoram uma ou outra publicação/repost sobre Direito Autoral. Há também, de forma unânime, interesse em participar de cursos, palestras e vivências artísticas.

Os artistas que foram os indivíduos-alvo desta pesquisa apontaram que o conteúdo de Direito Autoral pode se aproximar do seu fazer artístico por meio de palestras e cartilhas instrucionais que tenham como prioridade uma comunicação visual afeita às Artes Visuais e assim dialoguem com o seu cotidiano.

Durante a concepção do manual pela pesquisadora, os pontos levados em consideração foram: 1) natureza estética do manual; 2) formato digital com predominância da visualidade; 3) direcionamento a redes sociais; 4) download gratuito; 5) linguagem que envolva a realidade dos artistas; e 6) linguagem acessível com exemplos, etc.

Com relação ao conteúdo, a abordagem deve ser específica de direito autoral para artistas visuais, com ênfase nos direitos morais e patrimoniais, necessidade ou não de registro, poder de escolha pela flexibilização do creative commons, contratos, direito de sequência, limitações, etc.

Com relação às estratégias de divulgação, foi realizado um planejamento simples: 1) divulgação nas redes sociais da pesquisadora do link para download do manual (Instagram, Facebook e WhatsApp - https://drive.google.com/file/d/1GFxbJrfWH0R09f8yWsUsv18MOGolneyO/view); 2) disseminação na reunião mensal do Conselho Municipal de Políticas Culturais do Município de Maceió; 3) inserção da proposta de palestra para disseminação do conteúdo do manual no Edital de Chamada Pública n. 01/2019 da 9a Bienal Internacional do Livro de Alagoas, realizada pela Universidade Federal de Alagoas (UFAL), compondo o Congresso de Direito de Autor e outras Propriedade Intelectual com a organização da Comissão de Propriedade Intelectual da Ordem dos Advogados do Brasil em Alagoas; e 4) palestra e compartilhamento no manual, na reunião mensal do Projeto "Redes Criativas", do Sebrae/AL e do Setorial de Música.

\section{Referências}

BRASIL. Lei n. 9.610, de 19 de fevereiro de 1998. Altera, atualiza e consolida a legislação sobre direitos autorais e dá outras providências. Disponível em: http://www.planalto.gov.br/ccivil_03/leis/ 19610.htm. Acesso em: 22 mar. 2019.

EISENHARDT, Kathleen M., Building theory from case study research. Academy of Management Review, [s.l.], v. 14, n. 4, p. 532-550, 1989.

ENTREVISTA 1. Concedida a Jamilla de Paula dos Santos Almeida. Maceió, 1 jul. 2019.

ENTREVISTA 2. Concedida a Jamilla de Paula dos Santos Almeida. Maceió, 1 jul. 2019.

ENTREVISTA 3. Concedida a Jamilla de Paula dos Santos Almeida. Maceió, 2 jul. 2019.

ENTREVISTA 4. Concedida a Jamilla de Paula dos Santos Almeida. Maceió, 2 jul. 2019.

FIRJAN - FEDERAÇÃO DAS INDÚSTRIAS DO ESTADO DO RIO DE JANEIRO. Mapeamento da

Indústria Criativa no Brasil. 2016. Disponível em: https:/www.firjan.com.br/EconomiaCriativa/ downloads/MapeamentoIndustriaCriativa-Firjan2016.pdf. Acesso em: 5 abr. 2019. 
FIRJAN - FEDERAÇÃO DAS INDÚSTRIAS DO ESTADO DO RIO DE JANEIRO. Mapeamento da Indústria Criativa no Brasil. 2019. Disponível em: https:/www.firjan.com.br/EconomiaCriativa/ downloads/MapeamentoIndustriaCriativa.pdf. Acesso em: 5 abr. 2019.

FLEMING, Tom. A economia criativa brasileira: análise da Situação e avaliação do Programa de Empreendedorismo Social e Criativo Financiado pelo Newton Fund. [2018]. Disponível em: https:// www.britishcouncil.org.br/sites/default/files/brasil_economia_criativa_online2.pdf. Acesso em: 18 abr. 2019.

LINS, Cristina. Demanda e produção de informações culturais: parceria MinC e IBGE. In: CRIBARI, Isabela et al. (Org.). Economia da Cultura. Recife: Editora Massangana, 2009. p. 131-155.

MINC - MINISTÉRIO DA CULTURA; ITAÚ CULTURAL. Relatório de economia criativa 2010: economia criativa uma, opção de desenvolvimento. Brasília; São Paulo: Secretaria da Economia Criativa, 2012. Disponível em: https://unctad.org/system/files/official-document/ditctab20103_pt.pdf. Acesso em: 5 abr. 2019.

MORANDI, A. M. et al. Economia Criativa Capixaba: uma Proposta de Metodologia para o seu dimensionamento. In: VALIATI, L.; FIALHO, A. L. N. (org.). Atlas Econômico da Cultura Brasileira: metodologia I. Porto Alegre: Editora da UFRGS/CEGOV, 2017. p. 81- 101.

SAUNDERS, Mark et al. Research methods for business students. 5. ed. Harlow, England: Pearson Education, 2009.

SEBRAE - SERVIÇO BRASILEIRO DE APOIO ÀS MICRO E PEQUENAS EMPRESAS. Relatório de Gestão e Monitoramento do Projeto. Maceió, 2019. No prelo.

SEBRAE - SERVIÇO BRASILEIRO DE APOIO ÀS MICRO E PEQUENAS EMPRESAS. Planejamento Estratégico do SEBRAE 2019/2020. Maceió, 2019. (no prelo)

UNCTAD - UNITED NATIONS CONFERENCE ON TRADE AND DEVELOPMENT. Creative Economy Report 2010. New York: United Nations, 2010.

UNDP - UNITED NATIONS DEVELOPMENT PROGRAMME; UNESCO - UNITED NATIONS EDUCATIONAL, SCIENTIFIC AND CULTURAL ORGANIZATION. Creative Economy Report 2013. New York: United Nations, 2013.

VALIATI, L.; CORAZZA, R. I.; FLORISSI, S. O marco teórico-conceitual da Economia da Cultura e da Economia Criativa: uma revisão de contribuições selecionadas e de seus pressupostos. In: MINC/ FECAMP. Nota Técnica Projeto "Perspectivas da Economia da Cultura - um modelo de análise do caso brasileiro” Área: Indicadores e Metas Gerais, 2011.

YIN, Robert K. Estudo de caso: planejamento e métodos. 4. ed. Porto Alegre: Bookman, 2010. 


\section{Sobre os Autores}

\section{Jamilla de Paula dos Santos Almeida}

E-mail: jamilla.almeida@cedu.ufal.br

Mestra em Propriedade Intelectual e Transferência de Tecnologia para Inovação pela Universidade Federal de Alagoas em 2019.

Endereço profissional: Universidade Federal de Alagoas, Campus Arapiraca, Av. Manoel Severino Barbosa, s/n., Bom Sucesso, Arapiraca, AL. CEP: 57300-970.

\section{Patrícia Oliveira Areas}

E-mail: patricia.areas@univille.br Doutora em Direito pela Universidade Federal de Santa Catarina em 2010.

Endereço profissional: Universidade da Região de Joinville, Pró-Reitoria de Pesquisa e Pós-Graduação, Núcleo de Inovação e Propriedade Intelectual, Rua Paulo Malschitzki, n. 10, Zona Industrial Norte, Joinville, SC. CEP: 89219-710.

\section{Pierre Barnabé Escodro}

E-mail: pierre.vet@gmail.com

Doutor em Química e Biotecnologia pela Universidade Federal de Alagoas em 2011.

Endereço profissional: Universidade Federal de Alagoas, Pró-Reitoria de Pesquisa e Pós-Graduação, Campus A. C. Simões, Av. Lourival Melo Mota, s/n, Tabuleiro dos Martins, Maceió, AL. CEP: 57072-970. 